suggest that barbiturates commonly cause a clinically important degree of confusion in old people, which is reversible when the drugs are withdrawn.

The continuing widespread use of barbiturates by elderly outpatients is disquieting. Several years ago informed medical opinion hardened against using barbiturates for any purpose other than controlling epilepsy or as an anaesthetic induction agent. CURB (Campaign on the Use and Restriction of Barbiturates) was set up in 1975 with government support and has since distributed leaflets etc throughout the profession. Frequent editorials in the $B M \mathcal{F}^{:-:}$and other journals have emphasised the perils of barbiturates. With barbiturate prescribing declining at $7 \cdot 5^{\prime \prime}$, a year ${ }^{*}$ this campaign seemed to be succeeding throughout the country. Our results, however, indicate that this may be a complacent view. Our disconcerting figures show that over $40^{\prime \prime}$ "of old people referred to a geriatric outpatient service in Nottingham in 1973 were on barbiturates and that by 1976 this figure had actually risen to over $50^{\circ}{ }^{\prime}$. It is also surprising that after several years of campaigning about barbiturates and ataxia about $74^{\circ}$, of old people referred because of falls in 1976 were still being prescribed barbiturates. So in one town the message on barbiturates is still largely being ignored. In how many other areas of the country is this also happening?

\section{References}

${ }^{1}$ Drug and Therapeutics Bulletin, 1971, 9, 9

2 Townsend, P, and Wedderburn, D, The Aged in the Welfare State, p 24 London, Bell, 1965.

${ }^{3}$ Robinson, R A, in Assessment in Cerebrovascular Insufficiency, ed G Stocker et al, p 89. Stuttgart, Georg Thieme, 1971.

4 Rudd, T N, Gerontologica Clinica, 1972, 14, 123.

${ }^{5}$ British Medical fournal, 1974, 4, 552.

${ }^{6}$ British Medical fournal, 1975, 3, 725.

'British Medical fournal, 1976, 1, 1424.

${ }^{8}$ Johns, M W, British Medical fournal, 1977, 1, 1128.

(Accepted 22 fune 1977)

\title{
Effect of calcitonin treatment on deafness due to Paget's disease of bone
}

\author{
L R SOLOMON, J M EVANSON, D P CANTY, N W GILL
}

British Medical fournal, 1977, 2, 485-487

\section{Summary}

Seventeen patients with Paget's disease of the skull and deafness were followed for nine to 18 months. Patients who received calcitonin treatment showed less deterioration in hearing than untreated patients.

Calcitonin treatment may retard the progression of deafness in Paget's disease, and further studies are indicated.

\section{Introduction}

Deafness is an important complication of Paget's disease of bone. Almost half the patients with diagnosed skull disease develop hearing loss.' The nature of the deafness is complex. Typically there is mixed low-frequency conductive and highfrequency sensorineural loss but in some cases pure forms may occur..$^{1-3}$ Despite occasional reports of benefit, surgical intervention is not usually recommended, ${ }^{2+}$ and until recently a hearing aid has been the only effective treatment available.

Calcitonin treatment may relieve the pain and also improve the biochemical abnormalities of Paget's disease and there have been occasional reports of benefit to patients with neurological

Department of Medicine, University Hospital of South Manchester, Manchester M20 8LR

L R SOLOMON, MRCP, lecturer in medicine

J M EVANSON, FRCP, professor of medicine

Department of Otolaryngology, University Hospital of South Manchester, Manchester M20 8LR

D P CANTY, FRCS, senior registrar in ENT surgery

$\mathrm{N}$ W GILL, FRCS, consultant ENT surgeon complications, such as cranial nerve palsies and nerve compression syndromes. ${ }^{5}{ }^{6}$ It is not yet known whether or not continuous calcitonin treatment heips other features of the disease such as deafness, deformity, and radiological changes. We therefore investigated the effect of calcitonin treatment on the deafness of Paget's disease.

\section{Patients and methods}

During the first year of a special clinic for treating patients with Paget's disease of bone all patients were assessed clinically and audiologically for deafness. Seventeen patients who had a history of subjective deafness, radiological evidence of skull disease, and both low-tone conductive loss and high-tone sensorineural loss on a pure tone audiogram were selected for further study. Whenever possible these patients had serial pure-tone audiograms and underwent impedance audiometry every three months by the same audiotechnician. Biochemical follow-up included three-monthly measurements of serum calcium, phosphorus, and alkaline phosphatase concentrations. When biochemical resistance was suspected in patients on calcitonin treatment the acute hypocalcaemic response to the appropriate calcitonin was measured.?

Seven patients (aged 51-77) with severe bone pain or distressing cosmetic deformity - such as facial involvement in young womenhad continuous calcitonin treatment and three patients with skeletal pain were given intermittent courses of the hormone. The control group consisted of seven patients (aged 60-76) who were free of pain and in whom there were no specific indications for calcitonin treatment. The severity of deafness in the two groups was of similar degree. Salmon calcitonin $50-100 \mathrm{U}$ subcutaneously or porcine calcitonin 80-160 U intramuscularly was given six days a week either by the patient or by the district nurse.

\section{Results}

Most patients who complained of bone pain achieved substantial relief of symptoms from calcitonin treatment. No patient in the treated group noticed any substantial subjective improvement in hearing over the period of study. 
Four of the continuously treated patients achieved a lowered plateau level of serum alkaline phosphatase and three developed a rebound rise in alkaline phosphatase after an initial fall. The rebound occurred six to nine months after the start of treatment in cases 5 and 6 , and six months after a change from porcine to salmon calcitonin in case 7 (see case report). One of these patients (case 5) still showed acute hypocalcaemia after a test injection of calcitonin and may therefore be considered to have been still responding to calcitonin. In case 6 the hypocalcaemic response was not tested.

The results derived from the pure-tone audiograms are summarised in figs 1 and 2 . The air-bone gaps (in decibels) at 250, 500, 1000, 2000 , and $4000 \mathrm{H}_{\mathrm{z}}$ of both left and right ears were added together on each audiogram from every patient. The change in this total from the first audiogram was calculated as an index of conductive change. A positive figure indicates an increase in the size of the gap.

Similarly, a total change in air conduction at 2000,4000 , and $8000 \mathrm{H}_{\mathrm{z}}$ was calculated as an index of the high-frequency sensorineural component of deafness. Air conduction was used because bone conduction was not measured at $8000 \mathrm{H}_{\mathrm{z}}$ and the air-bone gap is small at these frequencies.

On both these indices the treated group tended to fare better than the untreated group. Thus, at the end of the period of observation the mean changes in the total air-bone gap and in the total air con-

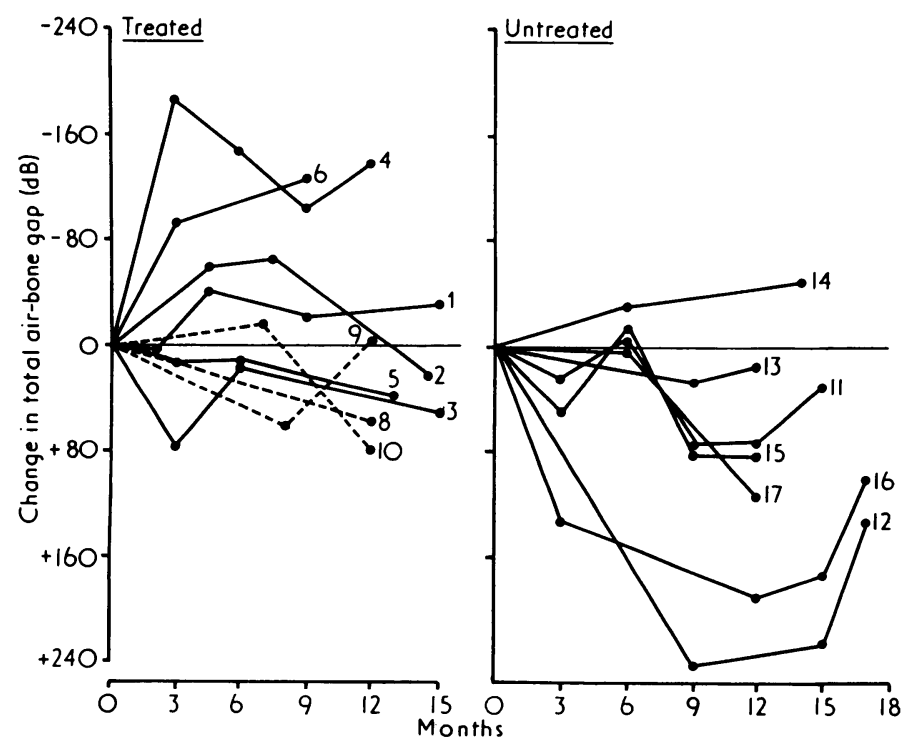

FIG 1-Change in total air-bone gap in treated and untreated patients. Dotted lines represent intermittently treated patients.

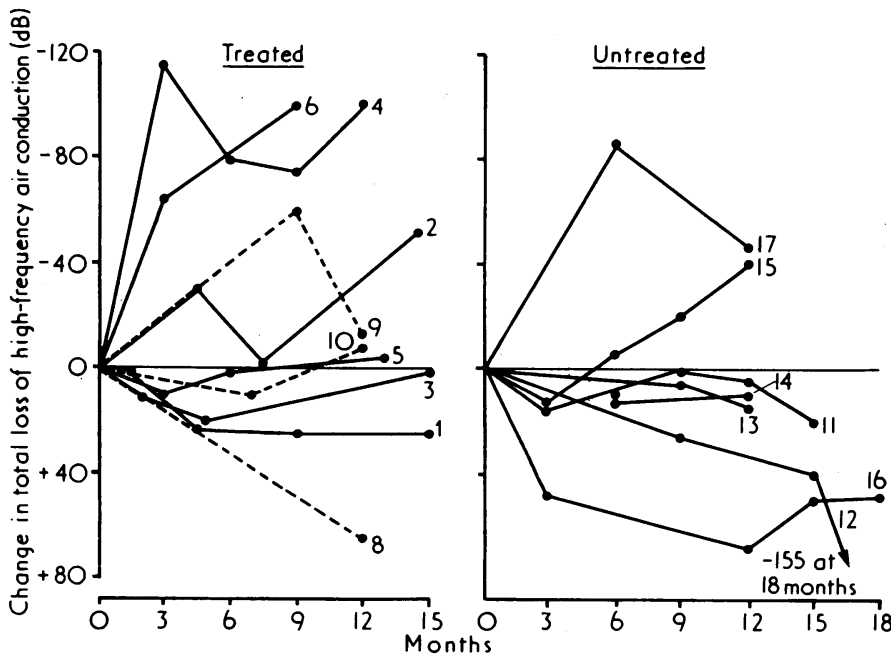

FIG 2-Change in total decibel loss of high frequency air conduction in treated and untreated patients. Dotted lines represent intermittently treated patients.

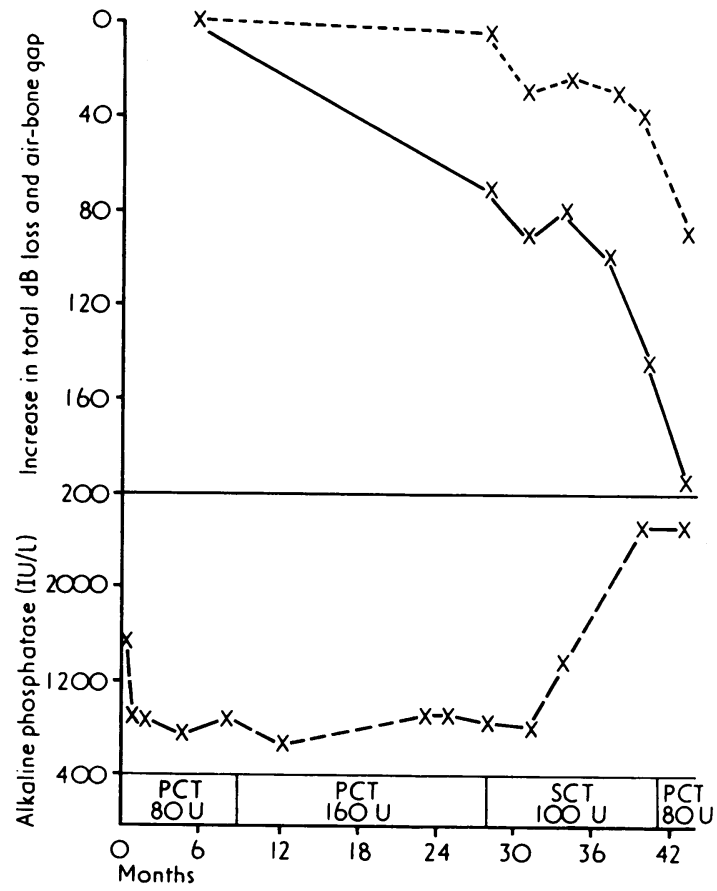

FIG 3-Case 7. Level of Serum alkaline phosphatase concentrations and change in total decibel loss at high-frequency air conduction (dotted line) and total air-bone gap (continuous line) during 43 months of calcitonin treatment. $\mathrm{PCT}=$ Porcine calcitonin. SCT $=$ Salmon calcitonin

duction at high frequencies were, respectively, $-12 \mathrm{~dB}$ and $-26 \mathrm{~dB}$ in the continuously treated "plateau responding" group compared with $+59 \mathrm{~dB}$ and $+17 \mathrm{~dB}$ in the untreated group.

The three patients who had intermittent calcitonin treatment showed intermediate values: at the end of the period of observation the mean changes in total air-bone gap and total high-frequency air conduction were $+45 \mathrm{~dB}$ and $+16 \mathrm{~dB}$ respectively.

One woman (case 7), who had been on continuous calcitonin treatment for over three years because of severe facial deformity deserves separate consideration.

Case 7-As a child this 53-year-old woman had suffered chronic secretory otitis media. At the age of 34 she had first noticed swelling in her upper jaw and subsequently she had suffered progressive enlargement of the skull and facial bones and her hearing had deteriorated. At presentation her main complaints were stabbing head pains and deafness, and there was obvious deformity of the facial bones. Skull radiographs showed extensive Paget's disease of the temporal bone. There was thinning and scarring of her left tympanic membrane and a healed central perforation in her right ear, and audiometry showed mixed conductive and sensorineural deafness. During the first two years of treatment with porcine calcitonin (fig 3 ) the serum alkaline phosphatase concentration maintained a plateau response, and serial audiograms showed a slight deterioration in hearing. About six months after she changed to salmon calcitonin the serum alkaline phosphatase concentration rose sharply, and acute challenge with salmon calcitonin produced no hypocalcaemic response. The patient was, therefore, judged to have become resistant to salmon calcitonin. Coincidental with the rebound rise in the alkaline phosphatase concentration was a striking increase in the rate of deterioration of her hearing.

\section{Discussion}

Various mechanisms have been implicated in the pathogenesis of Pagetoid deafness, and the mixed nature of the hearing loss makes the diagnosis of deafness due to Paget's disease difficult. ${ }^{12}$ Patients with this condition are usually old and may be deaf for other reasons. It is therefore not possible to determine accurately how much Paget's disease contributes to the deafness in any individual patient. Case 7 illustrates this problem. Although the patient had extensive Paget's disease affecting the temporal bones, she also gave a history of chronic suppurative otitis media. We selected only patients with radiological evidence of Paget's disease of the skull and typical audiological changes. It seemed 
reasonable to assume that Paget's disease was a major contributing factor to deafness in most of these cases.

Audiological assessment was confined to a clinical examination, and pure-tone and impedance audiometry. Tone decay and tests for recruitment and speech audiometry were not included because they do not clarify the diagnosis and they would have been confusing and tiring for a group of elderly patients. Temporal bone tomography was not undertaken because of the risks to the eye.

With these tests we have observed a trend for the conductive component and to a lesser degree the high-frequency sensorineural component of deafness to deteriorate less rapidly in patients on continuous calcitonin treatment than in untreated patients. Intermittently treated patients showed intermediate changes. The observations in case 7 suggest that hearing loss may be delayed though not actually prevented by effective calcitonin treatment.

Previous reports of the effect of calcitonin on deafness have shown conflicting results. Shai et al ${ }^{\times}$reported an improvement in air conduction at low frequencies in three out of six patients treated with porcine calcitonin for six to 17 weeks. Moffat et al ${ }^{9}$ reported a single case of improvement after 23 weeks' porcine calcitonin treatment. Neither of these studies included a control group and the patient described by Moffat et al had no evidence of Paget's disease in the skull. Grimaldi et al ${ }^{10}$ failed to show any change in the hearing of their patients who were treated with salmon or human calcitonin for 12 to 62 weeks, nor could Menzies et al ${ }^{11}$ show any improvement in the hearing of four patients treated with human calcitonin 1011 after 18-22 months.

In general the severity of deafness in Paget's disease is related to the extent of the bony disease, and most suggested mechanisms are related to the abnormal bone architecture. If long-term calcitonin treatment is effective in arresting the disease process or even in restoring bone structure to a more normal state then some benefit to hearing might be expected to occur, and our results suggest that this may indeed be so. Nevertheless, the number of patients, the period of observation, and the size of the changes are small. On the available evidence, deafness should not be regarded as an indication for calcitonin therapy in Paget's disease, but our findings suggest that further moreprolonged studies are needed.

We thank Mr L O'Neill who performed the audiograms and the department of medical illustration, University Hospital of South Manchester.

\section{References}

${ }^{1}$ Nager, G T, Annals of Otology, Rhinology and Laryngology, 1975, 84, suppl 22, No 4, part 3.

2 Davies, D G, Acta Oto-laryngologica, 1968, suppl No 242.

${ }^{3}$ Lindsay, J R, and Perlman, H B, Archives of Otolaryngology, 1936, 23, 580.

Waltner, J G, Archives of Otolaryngology, 1965, 82, 355

${ }^{5}$ DeRose, J, et al, American fournal of Medicine, 1974, 56, 858.

${ }^{6}$ Melick, R A, Ebeling, P, and Hjorth, R J, British Medical fournal, 1976, $1,627$.

${ }^{7}$ Haddad, J G, and Caldwell, J G, Fournal of Clinical Investigation, 1972, 51, 3133.

${ }^{8}$ Shai, F S, Baker, R K, and Wallach, S, fournal of Clinical Investigation, 1971, 50, 1927.

${ }^{9}$ Moffat, W H, Morrow, J D, and Simpson, N, British Medical fournal, $1974,4,203$.

10 Grimaldi, P M G B, Mohamedally, S M, and Woodhouse, N J Y, British Medical fournal, 1975, 2, 726 .

1 Menzies, M A, Greenberg, P B, and Joplin, G F, Acta Oto-laryngologica, $1975,79,378$.

\title{
Acceptability of an oral contraceptive that reduces the frequency of menstruation: the tri-cycle pill regimen
}

\author{
N B LOUDON, M FOXWELL, D M POTTS, A L GUILD, R V SHORT
}

British Medical fournal, 1977, 2, 487-490

\section{Summary}

The frequency of menstruation was reduced to once every three months in 196 women by the continuous administration of the oral contraceptive pill, Minilyn, for 84 days (tri-cycle regimen). No pregnancies occurred. One hundred and sixty-one women $(82 \%)$ welcomed the reduction in the number of periods with the as-

Family Planning Services, Lothian Health Board, Edinburgh

N B L.OUDON, MB, CHB, medical co-ordinator

M FOXWELL, SRN, nursing sister

International Pregnancy Advisory Services, Chapel Hill, North Carolina 27514, USA

D M POTTS, MB, PHD, director

Medical Research Council, Unit of Reproductive Biology, Edinburgh EH1 2QW

A L GUILD, MA, research technician

R V SHORT, SCD, FRS, director sociated freedom from menstrual and premenstrual symptoms, and many found the tri-cycle regimen easier to follow. Weight gain of more than $2 \mathrm{~kg}$, irregular cycle control, especially in the first three months, breast tenderness, and headaches were the main side effects. Menstrual loss was unchanged or reduced in all but seven women. The doctors and nurses on the clinic staff were less enthusiastic about this regimen than the volunteers themselves.

\section{Introduction}

When Dr Gregory Pincus first developed the oral contraceptive pill in the late 1950s he proposed a dosage regimen that would induce withdrawal bleeding every 28 days. Although the length of the cycle while on the pill is purely arbitrary, Pincus tried to imitate as closely as possible the length of the normal menstrual cycle to make the pill more acceptable when oral contraception was still a novel concept.

Since then the ability of synthetic ovarian hormones to control ovulation has been widely exploited, and it is now estimated that over 50 million women use the pill ${ }^{1}$; probably as many again have used it at some time. The pill has proved 